\title{
An Oral Health Awareness Comparison between Private Businessmen and Forwarding Agents
}

\author{
Seoul-hee Nam, Da-ye Cheon and Jeong-Min Seong ${ }^{\dagger}$ \\ Deptarment of Dental Hygiene Kangwon National University \\ jmseong@kangwon.ac.kr
}

\begin{abstract}
This study was performed to enhance the concern about oral health and introduce the importance about awareness and knowledge by ascertaining differences according to working types and environmental characteristics. This study was conducted with two target groups, 70 businessmen and 70 forwarding agents in Samcheok-si, Gangwon-do by a self-administered questionnaire survey included items regarding general characteristic, oral health surroundings care \& living habit, oral health awareness \& practice, and oral health concern from May 23, 2016 to May 31, 2016. And the collected data was analyzed by frequency analysis and t-test in SPSS v19.0. The result showed there were significant differences between two target groups in awareness about halitosis, auxiliary oral hygiene devices, dental health insurance, and experience \& importance about oral health education. This is an important factor that influences the effectiveness of education by finding out what workers want to know, what they want to learn, or what they need to know for themselves or their oral health promotion. The necessity of oral health education should be perceived and promoted through checking oral health surroundings care and analyzing awareness about oral health education experience \& importance between two target groups.
\end{abstract}

Keywords: Oral health, Education, Private businessmen.

\section{Introduction}

The concept of health is defined as 'Health means a physical, mental, and social wholesome status, not only a physical status which has no disease or weakness' in the charter of WHO[1]. The health right of people is defined as 'All people has a right to live in a healthy and comfortable environment, and country and the people put efforts on environment maintenance.' in the article 35-1. Likewise, health should be managed as the requisite to maintain national welfare[2]. As a part of overall health, oral health is recognized as an living element in nowadays; therefore, reasonable cares regarding oral health should be emphasized [3]. Oral health means the teeth and maxillofacial systemic organ status which have no disease, weakness, or disabilities for mental action and social life.

Oral health-related behavior of individuals and has the characteristics of socialpsychological process, which individual decisions dimensional why suited to explain why happened that such actions by the model, and an important factor in the belief that influence the various mouth-related behavior. Oral health beliefs is to explain the behavior and related factors take aim to understand oral health as a sociological process, and believe that the health model that describes people to prevent, discover the disease in the asymptomatic stage. Oral health beliefs was applied to the oral health sector by the later, it kegeles health belief model is applied to the health sector. According to the oral health belief model, the severity and disability of the oral health felt by various types of work such as working style, working hours, and working fields of workers in the workplace will be different. It will be possible when health beliefs and knowledge are 
established correctly. In other words, oral health care practices are closely related to knowledge and attitudes about oral health knowledge and attitudes about oral health can be changed via the oral health education[4]

Oral health of workers should be done through the group's oral health management system at the workplace, business establishment can make an oral health education for adults easy and it is reported as an efficient place. However, in the national health policy part, the importance of the oral health field is in a phase that can be cleared up in practice by secondary problems, and in the case of oral screening of workers, oral examination is increasingly lower It was until then to try to abolish even oral examination. Based on the fact that health of the oral cavity contributes to the development of the industry itself as well as prolonging the life expectancy of workers' teeth as part of overall health, improving oral health, Workers are subjects of industrial oral health and can be seen as important targets for oral health in adults.

Many adults can be classified as workers who spend most of their lives in the workplace. Workers are an important source of economic development and the health of workers is very important to the productivity of enterprises. Workers experience various stresses while performing work given to themselves in the work environment they belong to. The psychosocial health condition due to workers' stress and fatigue is a major factor that has a close influence on the overall physical and mental health conditions. Fatigue of workers is a state of fatigue caused by excessive physical and mental labor, and these fatigue conditions lead to a loss of function decline and to beat the day's motivation and efficiency. Workers, health level of the workers of the oral cavity has deteriorated to freely it is low oral care frequency of use for the business environment is going to affect the quality of life. - Objective clinical results related to health condition of the oral cavity were often used to evaluate the health condition of the oral cavity, but the social psychological effects perceived by the individual gradually subjective oral health recognition gradually there is a tendency to be interested in nonimasmic results such as. In Peruzzo et al.[5] studies, stress has been reported as a potential risk factor for periodontal disease among psychosocial factors, and Kleinhauz et al.[6] Discusses the relationship between stress and salivary glands Studies have reported that the function of the salivary glands due to stress decreases and xerostomia appears and may have difficulty in eating, talking, and having a younger age, and it is reported to develop inflammation and multiple caries on mucous membranes There. Inglehart and Tedesco [7] considers stress to be one of various factors affecting typical oral health behavior such as smoking cessation, oral hygiene control, diet adjustment, etc. Stress and diseases of the oral maxillofacial area Relating to the relationship between June and Hong [8] said various symptoms and signs such as xerostomia, bad breath, several oral mucosal diseases and mandibular disorders are correlated with stress. We assumed that the majority of our lives were spent in the workplace and the workers' stress increased and the health of the oral cavity was being threatened if we had to adapt to changes in the high-speed society. [9]

The purpose of study.education.practice in oral hygiene dentistry is to improve oral health status[1]. Oral health can be defined as "People have the teeth which make possible to have meals, conversations, and social activities without pains, disabilities, or discomforts functionally in life; and this contributes the overall personal well-being.", and this might be the requisite to maintain physical health and quality of life[5].

Most people are exposed to dental caries and periodontal diseases; however, cares as well as awareness about oral health are insufficient in a real situation. Oral health disasters which might happen in current business sites are not properly managed. Moreover, workers in business sites over certain scales might be received oral health cares in groups by public oral health methods, but workers in small business sites such as petty business site or home industry, etc have difficulties to approach public oral health benefits. Most adults manage their occupations and spend the most of time in working places. An individual person is not organized but only systematized in his business place 
or working site.

Therefore, with starting regular examination and early treatment (secondary prevention) in business sites, a group oral health care system might be the most efficient to prosecute oral health plans structurally and systematically.

Occupational oral disease might be occurred according to labor types or dealing materials in working sites. However, oral health cares seem to be negligent, so it should be included in the safety education program which current workers need to participate as a yearly basis [6]. Thus, researchers in this study guessed that working types \& environments of target groups might influence their awareness if we think about it based on one hypothesis, which forwarding agents have less awareness about oral health cares than private businessmen

In addition, the improvement of a certain health level for a certain group becomes visible when a comprehensive prevention, treatment, and education program lasts for a certain period of time. Therefore, if the content and method of oral health education tailored to the needs of workers in the workplace are provided, we will be able to maintain interest and improve your level of knowledge.

Besides, by checking oral health surroundings care \& living habit, oral health awareness \& practice, and concern of private businessmen and forwarding agents in Samcheok-si and comparing their awareness, we are plan to prepare the required basic data for oral health educations for improving the quality of worker's life as well as changing concerns, knowledge, attitudes, and behaviors for reasonable oral health cares.

\section{Study Target Materials and Methods}

\subsection{Study Target and Period}

This study was conducted with target groups, private businessmen and forwarding agents in Samcheok-si, Gangwon-do, from May 23, 2016 to May 31, 2016. We explained the purpose and use of this study to them at questionnaire distribution, and achieved a $100 \%$ return rate as an immediate collection. This survey was started with 90 private businessmen and 93 forwarding agents, and selected 90 targets respectively in two groups to make the same population. And then total 140 questionnaires were finally used in this study after excluding incomplete 40 papers.

\subsection{Study Method}

This survey was equally processed for all study targets and the questions were constructed as follows. 7 questions were in the general characteristic section such as sex, age, and job etc. 8 questions regarding meal frequency, smoking experience, and halitosis yes or no, etc were in the oral health surroundings care and living habit section. Besides, 9 questions regarding tooth-brushing frequency and auxiliary oral hygiene devices use experience etc were in the oral health awareness and practice section; and 10 questions regarding dental care insurance application and oral health education experience were in the concern about oral health section.

\subsection{Analysis Method}

In this study, collected data was converted into code and entered for an actual analysis; and SPSS v19.0 was used for the process and analysis. The statistic analysis method for data analysis is as follows. For study target's general characteristic and each item in this survey, a frequency analysis method was used; and for awareness comparison about halitosis, auxiliary oral hygiene devices, dental health insurance, and experience \& importance of oral health education, T-test was used. 


\section{Study Result}

\subsection{The Correlation of Halitosis and Auxiliary Oral Hygiene Device Use}

The result about study target's halitosis is as in Table 1. In this survey results, 'Yes in halitosis' respondents were 31 persons $(44.3 \%)$ and 'No in halitosis' respondents were 39 persons $(55.7 \%)$ in the private businessmen group; on the other hand, 'Yes in halitosis' respondents were 18 persons $(25.7 \%)$ and 'No in halitosis' respondents were 52 persons $(74.3 \%)$ in the forwarding agents group. Consequently, 'No in halitosis' respondents were more than 'Yes in halitosis' in both target groups, and the rate is higher in forwarding agents as 52 persons $(74.3 \%$ ) than private businessmen group as 39 numbers $(55.7 \%)$. In this analyzed result about halitosis comparison in two target groups, $\mathrm{p}$ value was indicated as 0.021 less than 0.05 ; therefore, there were significant differences $(\mathrm{p}<0.05)$.

\section{Table 1. Study Target's Halitosis}

\begin{tabular}{|c|c|c|c|c|c|}
\hline \multicolumn{2}{|c|}{ Characteristic } & $\begin{array}{c}\text { private } \\
\text { businessme } \\
\mathrm{n}\end{array}$ & $\begin{array}{c}\text { forwarding } \\
\text { agents }\end{array}$ & Total & \multirow{2}{*}{$\mathrm{p}^{*}$} \\
\hline \hline \multirow{2}{*}{ Halitosis } & Yes & $31(44.3)$ & $18(25.7)$ & $49(35.0)$ & \multirow{2}{*}{$0.021^{*}$} \\
\cline { 2 - 5 } & No & $39(55.7)$ & $52(74.3)$ & $91(65.0)$ & \\
\hline
\end{tabular}

\subsection{Auxiliary Oral Hygiene Device Use}

The auxiliary oral hygiene device use of study targets is as in Table 2 . The result showed that 'No Use' respondents were 39 persons (55.7\%), 'Dental Floss' respondents were 16 persons $(22.9 \%)$, 'Proxabrush' respondents were 7 persons $(10.0 \%)$, 'Tongue Cleaner' respondents were 4 persons (5.7\%), and 'Gargle' respondents were 4 persons $(5.7 \%)$ in the private businessmen group. The result showed that 'No Use' respondents were 28 persons $(40.0 \%)$, 'Dental Floss' respondents were 18 persons (25.7\%), 'Proxabrush' respondents were 7 persons (10.0\%), 'Tongue Cleaner' respondents were 4 persons (5.7\%), and 'Gargle' respondents were 4 persons (5.7\%) in the forwarding agents group. In this survey result about auxiliary oral hygiene device use comparison in two target groups, $\mathrm{p}$ value was indicated as 0.022 less than 0.05 ; therefore, there were significant differences $(\mathrm{p}<0.05)$.

Table 2. Auxiliary Oral Hygiene Device Use

\begin{tabular}{|c|c|c|c|c|c|}
\hline \multicolumn{2}{|c|}{ Characteristic } & $\begin{array}{c}\text { private } \\
\text { businessmen }\end{array}$ & $\begin{array}{c}\text { forwarding } \\
\text { agents }\end{array}$ & Total & \multirow{2}{*}{$\mathrm{p}^{*}$} \\
\hline \hline \multirow{2}{*}{$\begin{array}{c}\text { Auxiliary } \\
\text { Oral } \\
\text { Hygiene } \\
\text { Devices }\end{array}$} & No Use & $39(55.7)$ & $28(40.0)$ & $67(47.9)$ & \\
\cline { 2 - 5 } & Dental Floss & $16(22.9)$ & $18(25.7)$ & $34(24.3)$ & \multirow{2}{*}{$0.022^{*}$} \\
\cline { 2 - 5 } & Proxabrush & $7(10.0)$ & $8(11.4)$ & $15(10.7)$ & \\
\cline { 2 - 5 } & Tongue Cleaner & $4(5.7)$ & $3(4.3)$ & $7(5.0)$ & \\
\cline { 2 - 5 } & Gargle & $4(5.7)$ & $13(18.6)$ & $17(12.1)$ & \\
\hline
\end{tabular}

\subsection{Study Target's Awareness about Dental Health Insurance Application}

Study target's awareness about dental health insurance application is as in Table 3. 'Dentures' insurance applicable respondents were total 34 persons, which were 25 persons (35.7\%) of private businessmen and 9 persons (12.9\%) of forwarding agents. On the other hand, 'Dentures' insurance not-applicable respondents were total 106 persons (75.7\%), which were 45 persons $(64.3 \%)$ of private businessmen and 61 persons $(87.1 \%)$ of forwarding agents. The result significance probability of T-test was $0.001, \mathrm{p}$ value was 
less than 0.05 therefore there were significant differences $(p<0.05)$. In other words, 'Dentures' insurance applicable awareness of private businessmen was about 2.8 times higher than forwarding agents. Besides, 'Implant' insurance applicable respondents were total 34 persons $(24.3 \%)$, which were 24 private businessmen (34.3\%) and 10 forwarding agents $(14.3 \%)$. On the other hand, 'Implant' insurance not-applicable respondents were total 106 persons (75.7\%), which were 46 private businessmen $(65.7 \%$ ) and 60 forwarding agents $(85.7 \%)$. The result significance probability of T-test was $0.006, p$ value was less than 0.05 therefore there were significant differences $(p<0.05)$. Consequently, 'Implant' insurance applicable awareness of private businessmen was about 2.4 times higher than forwarding agents.

Table 3. Study Target's Awareness about Dental Health Insurance Application

\begin{tabular}{|c|c|c|c|c|c|}
\hline \multicolumn{2}{|c|}{ Characteristic } & $\begin{array}{c}\text { private } \\
\text { businessmen }\end{array}$ & $\begin{array}{c}\text { forwarding } \\
\text { agents }\end{array}$ & Total & \multirow{2}{*}{$\mathrm{p}^{*}$} \\
\hline \hline \multirow{3}{*}{ Dentures } & Applicable & $25(35.7)$ & $9(12.9)$ & $34(24.3)$ & \multirow{2}{*}{$0.001^{*}$} \\
\cline { 2 - 5 } & $\begin{array}{c}\text { Not } \\
\text { applicable }\end{array}$ & $45(64.3)$ & $61(87.1)$ & $106(75.7)$ & \multirow{2}{*}{$0.006^{*}$} \\
\hline \multirow{3}{*}{ Implant } & Applicable & $24(34.3)$ & $10(14.3)$ & $34(24.3)$ & \\
\cline { 2 - 5 } & $\begin{array}{c}\text { Not } \\
\text { applicable }\end{array}$ & $46(65.7)$ & $60(85.7)$ & $106(75.7)$ & \\
\hline
\end{tabular}

\subsection{Study Target's Oral Health Education}

Table 4 showed the result, which analyzed the difference between private businessmen and forwarding agents. Regarding 'oral health education experience'. The analysis result had significant differences statistically $(\mathrm{p}<0.05) .11$ persons $(15.7 \%)$ of forwarding agents were answered that they have experienced oral health education. On the other hand, 21 persons $(30.0 \%)$ of private businessmen were answered that they have experienced oral health education. So private businessmen had about two times more oral health education experiences than forwarding agents.

Table 4. Study Target's Oral Health Education

\begin{tabular}{|c|c|c|c|c|c|}
\hline \multicolumn{2}{|c|}{ Characteristic } & $\begin{array}{c}\text { private } \\
\text { businessmen }\end{array}$ & $\begin{array}{c}\text { forwarding } \\
\text { agents }\end{array}$ & Total & \multirow{2}{*}{$\mathrm{p}^{*}$} \\
\hline \hline \multirow{2}{*}{$\begin{array}{c}\text { Oral Health } \\
\text { Education }\end{array}$} & Yes & $21(30.0)$ & $11(15.7)$ & $32(22.9)$ & \multirow{2}{*}{$0.045^{*}$} \\
\cline { 2 - 5 } & No & $49(70.0)$ & $59(84.3)$ & $108(77.1)$ & \\
\hline
\end{tabular}

\subsection{Study Target's Importance Awareness about Oral Health Education}

In the analysis result of 'Importance Awareness about Oral Health', 'Very Important' was the highest value in both groups as 36 persons (51.4\%) in 70 private businessmen and 41 persons $(58.6 \%)$ in 70 forwarding agents. The next highest was 'Important' as 38 persons $(27.1 \%)$, and then 'Normal' as 10 persons $(7.1 \%)$, 'Not Very Important' as 9 persons (6.4\%), and 'Not Important' as 6 persons (4.3\%) in both groups in Table 5. 
Table 5. Target's Importance Awareness about Oral Health

\begin{tabular}{|c|l|c|c|c|c|}
\hline \multicolumn{2}{|c|}{ Characteristic } & $\begin{array}{c}\text { Private } \\
\text { businessmen }\end{array}$ & $\begin{array}{c}\text { Forwardin } \\
\text { g agents }\end{array}$ & Total & \multirow{2}{*}{$\mathrm{p}^{*}$} \\
\hline \hline \multirow{4}{*}{$\begin{array}{c}\text { Awareness } \\
\text { about Oral } \\
\text { Health } \\
\text { Importance }\end{array}$} & $\begin{array}{l}\text { Not Very } \\
\text { mportant }\end{array}$ & $7(10.0)$ & $2(2.9)$ & $9(6.4)$ & \\
\cline { 2 - 5 } & Not Important & $5(7.1)$ & $1(1.4)$ & $6(4.3)$ & \multirow{2}{*}{$0.028^{*}$} \\
\cline { 2 - 5 } & Normal & $6(8.6)$ & $4(5.7)$ & $10(7.1)$ & \\
\cline { 2 - 5 } & Very Important & $16(22.9)$ & $22(31.4)$ & $38(27.1)$ & \\
\hline
\end{tabular}

\subsection{Study Target's Oral Health Awareness}

Table 6 showed as seen by comparing the breath of whether private businessmen and forwarding agents companies because the $\mathrm{p}$ value is less than 0.05 to 0.021 can be seen that significant differences $(\mathrm{P}<0.05)$.

Table 6. Study Target's Oral Health Awareness

\begin{tabular}{|c|c|c|c|c|}
\hline \multicolumn{2}{|l|}{ Characteristic } & $\begin{array}{l}\text { Private } \\
\text { Businessmen (\%) }\end{array}$ & $\begin{array}{l}\text { Forwarding } \\
\text { Agents (\%) }\end{array}$ & Total $(\%)$ \\
\hline \multirow{2}{*}{$\begin{array}{l}\text { Oral Health } \\
\text { Education Status }\end{array}$} & Yes & $21(30.0)$ & $11(15.7)$ & $32(22.9)$ \\
\hline & No & $49(70.0)$ & $59(84.3)$ & $108(77.1)$ \\
\hline \multirow{5}{*}{$\begin{array}{l}\text { The number of } \\
\text { appropriate oral } \\
\text { health education }\end{array}$} & Not needed & $14(20.0)$ & $8(11.4)$ & $22(15.7)$ \\
\hline & Once a week & $8(11.4)$ & $2(2.9)$ & $10(7.1)$ \\
\hline & Once a month & $10(14.3)$ & $11(15.7)$ & $21(15.0)$ \\
\hline & Yearly & $27(38.6)$ & $34(48.6)$ & $61(43.6)$ \\
\hline & Twice a year & $10(14.3)$ & $15(21.4)$ & $25(17.9)$ \\
\hline \multirow{5}{*}{$\begin{array}{l}\text { Oral } \\
\text { administration of } \\
\text { conformity in } \\
\text { accordance with } \\
\text { the Working } \\
\text { Environment }\end{array}$} & Very Poor & $10(14.3)$ & $3(4.3)$ & $13(9.3)$ \\
\hline & $\mathrm{Bad}$ & $7(10.0)$ & $4(5.7)$ & $11(7.9)$ \\
\hline & usually & $37(52.9)$ & $38(54.3)$ & $75(53.6)$ \\
\hline & good & $12(17.1)$ & $22(31.4)$ & $34(24.3)$ \\
\hline & Very Good & $4(5.7)$ & $3(4.3)$ & $7(5.0)$ \\
\hline \multirow{8}{*}{$\begin{array}{l}\text { Not satisfied } \\
\text { with the current } \\
\text { oral condition }\end{array}$} & Bad Breath & $2(2.9)$ & $5(7.1)$ & $7(5.0)$ \\
\hline & Calculus & $4(5.7)$ & $1(1.4)$ & $5(3.6)$ \\
\hline & Periodontal Disease & $(0.0)$ & $1(1.4)$ & $1(0.7)$ \\
\hline & $\begin{array}{c}\text { Author discomfort } \\
\text { caused by tooth } \\
\text { loss }\end{array}$ & $3(4.3)$ & $0(0.0)$ & $3(2.1)$ \\
\hline & Stains & $2(2.9)$ & $3(4.3)$ & $5(3.6)$ \\
\hline & $\begin{array}{l}\text { Aesthetic defects } \\
\text { due to loss of teeth }\end{array}$ & $0(0.0)$ & $2(2.9)$ & $2(1.4)$ \\
\hline & Malocclusion & $0(0.0)$ & $3(4.3)$ & $3(2.1)$ \\
\hline & No answer & $57(81.3)$ & $53(75.7)$ & $110(78.6)$ \\
\hline Total & & $70(100)$ & $70(100)$ & $140(100.0)$ \\
\hline
\end{tabular}




\section{Discussion}

This study was performed to ascertain the necessity for oral health education through awareness comparison and result analysis about oral health care, and the correlation analysis between occupation and oral health surroundings care \& living habit, the practice \& concern etc of private businessmen and forwarding agents in Samcheok-si, Gangwondo. In this thesis, survey was conducted with 140 targets of two different occupational clusters, the differences between two groups were predicted awareness and practice levels about oral health according to working environments.

In the analyzed result from each item according to occupations, significant levels were indicated in halitosis, auxiliary oral hygiene device use, dental health insurance application understanding, oral health education experience, and oral health importance awareness.

In the practice level in the 'auxiliary oral hygiene device use' section, 'No use' respondents were 39 private businessmen (55.7\%) and 28 forwarding agents (40.0\%).

On the other hand, in the 'Importance Awareness about Oral Health' item, the rate of 'Very Important' was the highest, which were answered by 36 private businessmen $(51.4 \%)$ and 41 forwarding agents $(58.6 \%)$.

Thus, if oral health education is conducted as considering working environments, the practice level according to awareness might be increased.

In consideration of the age group, they were in mostly 50s who have less opportunities to approach oral health education due to occupational characteristics, appropriate educations should be provided. Besides, the content of oral health education should be fitted with each personal oral health status.

Bigge(1967) and Bakdash(1979) emphasized importance about motivation. A patient, Lee Eun Suk(1996) said that oral health education was effective by self-motivation and consistent concerns about oral health[7]- [10]. Thus, we think that periodical education and self-care area should be improved.

Researchers had limitations in figuring out exact working hours by closed questions. In comparison self-administered weekly average working hours with work related activity time from timediary of same respondents, this has an advantage because the effect of two measurement methods can be evaluated in the most similar time during survey period[11]. Thus, if self-administered items are used as considering specific working hours, target's working hours might be clearly checked. In the similar thesis, 'Oral Health Awareness, Knowledge, and Behaviors Comparison Study of Junior and High School Students in City and Local District', adolescents' awareness about oral health were compared by regional differences. In this thesis, differences about oral health awareness were influenced by environmental factors such as districts, etc[12].

Therefore, to improve knowledge about oral health, we sensed the necessity of oral health education according to job environment, and considered oral health education should be the center of oral health activity because this education might give a profound effect on quality of life as well as oral health awareness.

To prevent oral disease, personal cares other than professional treatments are very important. The statement is defined as 'People should learn appropriate knowledge about oral health cares, cooperate with oral health business for the effective implementation, and put efforts for oral health and the promotion.' in the article 4 of Dental Health Act[13][14].

Workers are an important source of economic development, and the health of workers is a very important factor not only for the individual but also for the productivity of the enterprise. Oral health has also become increasingly important as an integral part of mental health and industrial oral health to promote the oral health of workers [18].

According to S.H Kim and M.H. Hong emphasized "A study on the Differences in selfperceived Oral Health Levels in Workers at Seoul-Incheon Area", Oral health promotion 
projects should be differentiated by suggesting that awareness of oral health levels is different between workers in production and office workers. Workers should be encouraged to take oral health care through their preventive and continuing oral health care program because they are often neglected in their preventive activities while they are interested in their tooth condition [19]. Also, In order to improve the oral health of the workers in the workplace, basic data on the current thinking and behaviors of their oral health should be prepared. In order to do this, it is essential that data on workers' awareness of oral health education is provided. This is an important factor that influences the effectiveness of education by finding out what workers want to know, what they want to learn, or what they need to know for themselves or their oral health promotion[20] . Currently, most oral health workers in Korea are focusing on oral disease treatment. However, in order to reduce the incidence of new oral diseases, prevention through oral health education should be given priority. In addition, we will have to try for as the dental hygienist as a dental hygienist as a dental hygienist, the dental hygienist has a duty to provide oral hygiene education based on more reliable evidence for changing the perception of the patient. [21]

Because workers need to adapt to the rapid changes in modern society while sending a substantial part of their lives in the industrial chapter, stress increases with excessive work volume, poor working environment, conflicts within the organization, Threatening the health of workers. Also health of workers is an important factor that greatly affects productivity in modern society, occupational health to maintain and promote health of workers is very important [22]. It is also important to improve the health of the oral cavity of workers in connection with this, and the health promotion of workers' mouths will increase the worker's sense of work satisfaction and improve the cost and productivity And it is reported that it contributes greatly to the improvement of the quality of life[23]. Because most workers have few opportunities to visit a dental office compared to nonworkers on the basis of work conditions, it is difficult to find oral disease early and to treat early, so regular checkups of oral health By periodically providing opportunities for oral health education and oral health consultation to raise workers' oral health awareness, we can make early discovery of oral consumer price index possible to lead to initial treatment [24].

Therefore, this type of education will be worthy for further improvements about the quality of worker's life related oral health.

\section{Conclusions}

In this study, there were significant differences between two groups, private businessmen and forwarding agents, in halitosis, auxiliary oral hygiene device use, dental health insurance applicable awareness, and oral health education experience \& importance understanding. Especially in knowledge about oral health, private businessmen had more knowledge than forwarding agents. On the other hand, in fixced-choice item regarding awareness about oral health importance, the numbers of forwarding agents responded as 'Important' and 'Very Important' were more than private businessmen. However, in oral health education experience, the numbers of private businessmen were about two times more than forwarding agents. Also, Samcheok-si belongs to small city. People living in rural areas tend to have less opportunity to acquire oral health knowledge than those who live in urban areas, have more time and space constraints to receive medical benefits, tend to postpone medical practices with traditional and conservative characteristics, In the case of a problem or a deterioration in health condition [22].

Therefore, private businessmen had less awareness about importance of oral health education because they had more knowledge about oral health; in contrast, forwarding agents had better awareness about importance of oral health education because they had comparatively lower knowledge about oral health. Therefore, in order to improve the oral 
health knowledge, I felt the need for oral health education, because education is the oral cavity exert a profound influence on the perception and quality of life is suggested that oral health education is to be a center of oral health activities.

\section{Acknowledgements}

This paper is a revised and expanded version of a paper entitled [Study on the Receiver Performance in a Wireless Network using Turbo Code] presented at [Proceedings International Conferences, August 19-20, 2016, Harbin, China, NGCIT 2016].

\section{References}

[1] B. W. Kang, H. K. Kang and I. Y. Koo, "Preventive Dentistry", vol. 5, (2014), pp. 3-5.

[2] B. W. Kang, J. O. Kang and J. S. Kwak, "Public Oral Health", vol. 4, (2015), pp. 7-8.

[3] J. B. Kim, Y. J. Cho and H. S. Moon, "Public Oral Health", vol. 4, (2015), pp. 2.

[4] S. H. Kim, M. H. Hong "A study on the Differences in self-perceived Oral Health Levels in Workers at Seoul-Incheon Area", vol. 12, no. 12, pp. 6-8

[5] D. C. Peruzzo, B. B. Benatti and G. M. Ambrosano, "Asystematic review of stress and psychological factors as possible risk factor for periodontal disease", Journal Periodontal, vol. 78, (2007), pp. 14911504.

[6] I. E. M. Kleinhauz, R. Baut and M. Littner, "Antecedents of burning mouth syndreome: recent life ebent vs. Psychopathologic aspects", Journal Dent Res, vol. 73, (1994), pp. 357-572.

[7] M. Inglehart and L. A. Tedesco, "Behavioral research related to oral hygiene practices : a new century model of oral health promotion", Periodontao, vol. 8, (1995), pp. 15-23.

[8] Y. H. June and J. P. Hong, "Stress and oral disease", Korean Journal Str Res,vol. 3, (1995), pp. 57-72.

[9] D. I. Lee and S. J Han, "Research Article : Factors Which Affect the Oral Health-Realted Quality of Life of Workers, vol. 13 no. 4, (2013).

[10] K. S. Ahn and M. A. Shin, "Association between oral health status and oral health impact profile(OHIP14) among the community elderlies", Korean Academy of Dental Hygiene Education, vol. 11, no. 6, (2011), pp. 923-938.

[11] K. S. Kim, Y. S. Hwang and Y. K. Kim, "Community Dental Health Status”, vol. 6, Gomunsa, (2010), pp. 33-212.

[12] M. L. Bigges, "Learning theories for teachers", NY: Harper \& ROW, (1967), pp. 290.

[13] M. Bakdash, "Patient motivation and education-A conceptual model", Journal of Clinical Preventive Dentistry, (1979).

[14] E. S. Lee, "Introduction to Dental Hygiene", Gomunsa, (1996).

[15] H. S. Cho and S. H. Hwang, "Impact of Oral Health Education on the Oral Health Knowledge, Attitude, and Behavior of College Students", The Journal of Korean Society for School Health Education, vol. 11, no. 1, (2010), pp. 7-15.

[16] H. J. Kim, S. J. Moon and K. Y. Lee, "Nutritional and Health Status of Nurses, Medical Doctors and Factory Workers", The Korean Journal of Nutrition Society, vol. 13, no. 3, (1980), pp. 126-133.

[17] M. J. Kim, H. J. Yang and S. Y. Lee, "A Comparative Study on Dental Health awareness and Dental Health Behaviors among Middle and High School Students in the Urban and Rural", The Korean Journal of Health Service Management, vol. 6, no. 4, (2012), pp. 215.

[18] B. W. Kang, M. H. Go and Y. K. Kim, "Medical Legislation", Gomunsa, (2006), pp. 437-439.

[19] N. Seoul-hee, G. A-ra, P. Hyo-soo, B. Min-jeong, L. Hyeon-jeong, C. H. Choi, B. I Kim, H. K Kwon, "Dental erosion prevalence and risk factors in galvanizing and battery manufacture factory workers", Journal Korean Acad Dent Health, vol. 26, (2002), pp. 535-554.

[20] H. D. Kim, D. H. Koh, W. C. Park and J. B. Kim "Realationship between major oral diseases adn work loss", Journal Korean Ind Dent Health Assoc, vol. 14, (2004), pp. 39-53.

[21] B. J. Chang and S. K. Lee, "Public health dentisrtry : A Studyon utilization of worker's dental services : an application of theory of planned behavior", Journal Korean Acad Dent Health, vol. 32, (2008), pp. 587-599.

[22] J. Eun-bi, C. Da-ye and S. Jeong-Min, "ITC Ages Importance of Oral Hygiene in accordance with the job characteristics," Proceedings International Conferences, August 19-20, 2016, Harbin, China, vol. 138, (2016), pp. 62-75.

[23] E. J Kim and S. H Woo, "Relationship of Oral Health Education Experience to oral Health Awareness among Shipbuilding Workers", vol. 12, no. 7, (2012), p. 4.

[24] J. R Song, H. W Oh and H. S. Lee, "Workers' Oral Health Behavior and Need for Education in Iksan city", Journal of Krean Academy of Oral Health, vol. 31, (2007), pp. 91-102.

[25] M. H Lim, "A Study on the Oral-Health Belief and Oral-Health Care of Company Emplotees", Korean Society Dental Hygiene, vol. 8, no. 4, (2008), pp. 205-217.

[26] H. Y. Oh, E. J. Kim and S. Y. Ahn, "Oral Care in Resulting in Oral Health Education in Oral Health 
Attitudes and Awareness of Relevant Research”, vol. 14, no. 3, (2012), pp. 156-157.

[27] Y. Jeagal and S. Y. Cho, "Comparative Research on the Basic Knowledge of Oral Health of Parents of Children Living in Rural and Urban Area”, vol. 7, no. 2, (2001), pp. 109-117.

\section{Authors}
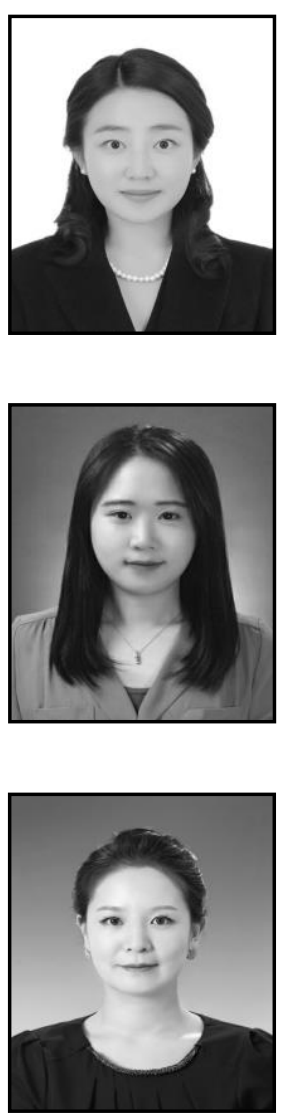

Jeong-Min Seong, she received her M.S, and Ph. D degrees in dentistry in 2008, and 2012, respectively, from the Yonsei, Kyung Hee University, Korea. She joined, Kangwon National University where she is currently as professor in the department of Dental Hygiene. Her research interests include a clinical hygiene, dental materials. 